\title{
De invloed van rolmodellen op de specialismekeuze van toekomstige artsen
}

\author{
J. van den Berg, J.J.D.J.M. Rademakers, Th.J. ten Cate
}

\section{Samenvatting}

Inleiding: De beroepskeuze van medisch studenten is afhankelijk van verschillende factoren. Naast onder andere persoonlijke kenmerken en eerdere ervaringen in een specialisme, kunnen ook rolmodellen een belangrijke rol spelen. Mogelijk is de ondervertegenwoordiging van vrouwelijke medisch specialisten en hoogleraren mede veroorzaakt door een gebrek aan vrouwelijke rolmodellen.

Methode: Er is een literatuurstudie verricht. Met behulp van Medline en andere zoekmachines is er gezocht naar nationale en internationale literatuur over het onderwerp. De kenmerken en eigenschappen van rolmodellen, en het effect en gebruik van een rolmodel zijn onderzocht. Waar mogelijk is er gekeken naar verschillen tussen mannen en vrouwen.

Resultaten: Er zijn tien relevante publicaties gevonden over de invloed van rolmodellen op de beroepskeuze van geneeskundestudenten. Zes studies vinden een positieve relatie tussen het rolmodel en de beroepskeuze van de student. Eén studie vindt geen duidelijk positief effect. Twee studies geven aan dat vrouwelijke rolmodellen in de chirurgie een belangrijke rol kunnen spelen in de beroepskeuze voor chirurgie van vrouwelijke studenten.

Conclusie en discussie: Rolmodellen kunnen een belangrijke rol spelen in de beroepskeuze van geneeskundestudenten. Faculteiten en specialismen kunnen van dit gegeven gebruik maken door rolmodellen op de juiste plaatsen in het medisch onderwijs in te zetten. (Berg J van den, Rademakers JJDJM, Cate ThJ ten. De invloed van rolmodellen op de specialismekeuze van toekomstige artsen. Tijdschrift voor Medisch Onderwijs 2006;25(5):227-234.)

\section{Inleiding}

Het kiezen van een specialisme in de geneeskunde is ingewikkeld. Sommige studenten hebben hun keuze al gemaakt voordat ze aan de studie beginnen, terwijl anderen zelfs na het afstuderen nog twijfelen. Het kiezen van een specialisme is een uitgebreid en ingewikkeld proces, waarbij veel factoren betrokken zijn. Uit verschillende onderzoeken blijkt dat persoonlijke kenmerken van de student, de levensstijl die past bij het toekomstige beroep, de invulling van het curriculum, de ervaring met het beroep tijdens het gelopen coschap, het salaris en de aanwezigheid van een rolmodel, invloed hebben op de carrièrekeuze. ${ }^{1-4}$
In dit artikel wordt ingegaan op de invloed van rolmodellen op de keuze voor een specialisme. Op grond van gegevens uit onderzoeksliteratuur wordt gekeken naar het begrip 'rolmodel', welke kenmerken en eigenschappen studenten belangrijk vinden in een rolmodel, de invloed van rolmodellen op studenten in het algemeen en op de beroepskeuze in het bijzonder, en de mogelijke (actieve) toepassingen van rolmodellen in de geneeskunde.

Bij de bespreking van de literatuur wordt, waar mogelijk, ingegaan op verschillende effecten van rolmodellen voor mannelijke en vrouwelijke studenten. Er is in de geneeskunde sprake van een asymmetrische verdeling van de seksen over de 
verschillende specialismen. In 1990 werden de meeste specialismen gedomineerd door mannen, met als uitzonderingen de klinische genetica, kindergeneeskunde, klinische geriatrie, revalidatiegeneeskunde, verpleeghuisgeneeskunde, arts voor verstandelijk gehandicapten en maatschappij en gezondheid. ${ }^{5}$ Deze situatie is in 2004 weinig veranderd. ${ }^{6}$ Hoewel er meer vrouwelijke artsen zijn afgestudeerd sinds 1990, is er nog steeds een klein aantal specialismen waarin meer dan $50 \%$ vrouw is: allergologie, klinische genetica, klinische geriatrie, verpleeghuisgeneeskunde en arts voor verstandelijk gehandicapten. Er bestaan geen specialismen waarin meer dan $80 \%$ vrouw is, terwijl dit voor mannen in een groot aantal specialismen geldt. ${ }^{6}$ Ook stromen weinig vrouwen door naar hogere functies. Slechts $7 \%$ van de hoogleraren in de geneeskunde is vrouw. ${ }^{7-8}$

Er zijn verschillende oorzaken voor deze ondervertegenwoordiging van vrouwen in bepaalde specialismen en functies. ${ }^{9}$ Ten eerste denken veel vrouwen dat een carrière in een bepaald specialisme moeilijk te combineren zal zijn met een gezinsleven, waardoor de beroepskeuze wordt beperkt. Ook hebben vrouwen het gevoel beter te moeten presteren dan hun mannelijke collega's om als gelijke te worden ervaren; de prestatiedruk is daardoor groter. Tegelijkertijd zijn vrouwen minder competitief en is zichzelf profileren voor hen een groter probleem dan voor mannen. Vrouwen worden ook vaker ontmoedigd in het kiezen voor een medische carrière. Een laatste factor die herhaaldelijk genoemd wordt is het ontbreken van vrouwelijke rolmodellen in de geneeskunde. ${ }^{7}$ 9-10 Hierdoor zouden ze minder gestimuleerd worden om een bepaald specialisme te kiezen of een hoge functie te ambiëren. In dit artikel wordt nagegaan wat hier uit onderzoek over bekend is.

\section{Methode}

Er is een literatuurstudie verricht naar de invloed van het rolmodel op de carrièrekeuze van toekomstige artsen. Met behulp van Medline is gezocht naar internationale literatuur over dit onderwerp, gepubliceerd na 1980. Als zoektermen werden gebruikt: 'role model' in combinatie met 'student', 'medicine', 'female' of 'medical specialist'. De abstracts van de gevonden artikelen werden gescreend op relevantie. Artikelen met als onderwerp '(vrouwelijke) rolmodellen in de geneeskunde' en 'rolmodellen voor studenten' werden geïncludeerd als er sprake was van een cohortstudie met een duidelijke definitie van een 'rolmodel'. Geëxcludeerd werden artikelen gepubliceerd voor 1980 en artikelen die niet systematisch waren opgezet, zoals expert opinions. In totaal werden op deze manier tien publicaties geselecteerd.

\section{Resultaten}

\section{Definitie van een rolmodel}

De definitie van een 'rolmodel' is volgens de Van Dale ${ }^{\circledR}$ : “iem. die of iets dat op voorbeeldige wijze voldoet aan een bepaald rolpatroon". ${ }^{11}$ In de internationale medische literatuur wordt een rolmodel beschreven als 'a person considered as a standard of excellence to be imitated' 12-15 en als 'someone who has influenced the student to choose the same speciality as the role model'. ${ }^{16}$ Het is dus een arts, die de student laat zien hoe hij of zij later als arts wil of moet zijn en functioneren.

De term 'rolmodel' komt oorspronkelijk uit de sociale leertheorie van Bandura, waarin 'modeling' (leren door het observeren en imiteren van een rolmodel') wordt beschreven. ${ }^{17}$ 'Modeling' bestaat uit vier samenhangende principes in het leerproces: aandacht, onthouden, uitvoeren en motiveren. In een studie van Altouse et al. wordt de toepassing van deze 
principes onderzocht in de klinische setting. ${ }^{18}$ Aandacht wordt getrokken door studenten het enthousiasme voor het vak en het onderwijs te demonstreren. Door herhaling en ondervraging wordt informatie onthouden. Vervolgens wordt de geleerde informatie toegepast en uitgevoerd in de klinische setting. De motivatie wordt aangeleerd door studenten het plezier in het vak te laten zien en zelf te laten ervaren.

\section{Kenmerken en eigenschappen}

Er is onderzocht wat de kenmerken en eigenschappen zijn die studenten belangrijk vinden in een rolmodel. In tabel 1 is te zien wat studenten het meest en minst belangrijk vinden.

Een onderzoek van Wright et al. ${ }^{14}$ beschrijft dat artsen, die als rolmodel worden beschouwd, vaker:

- verantwoordelijkheid hebben voor onderwijs;

Tabel 1. De kenmerken en eigenschappen van een rolmodel. ${ }^{12-13} 17$

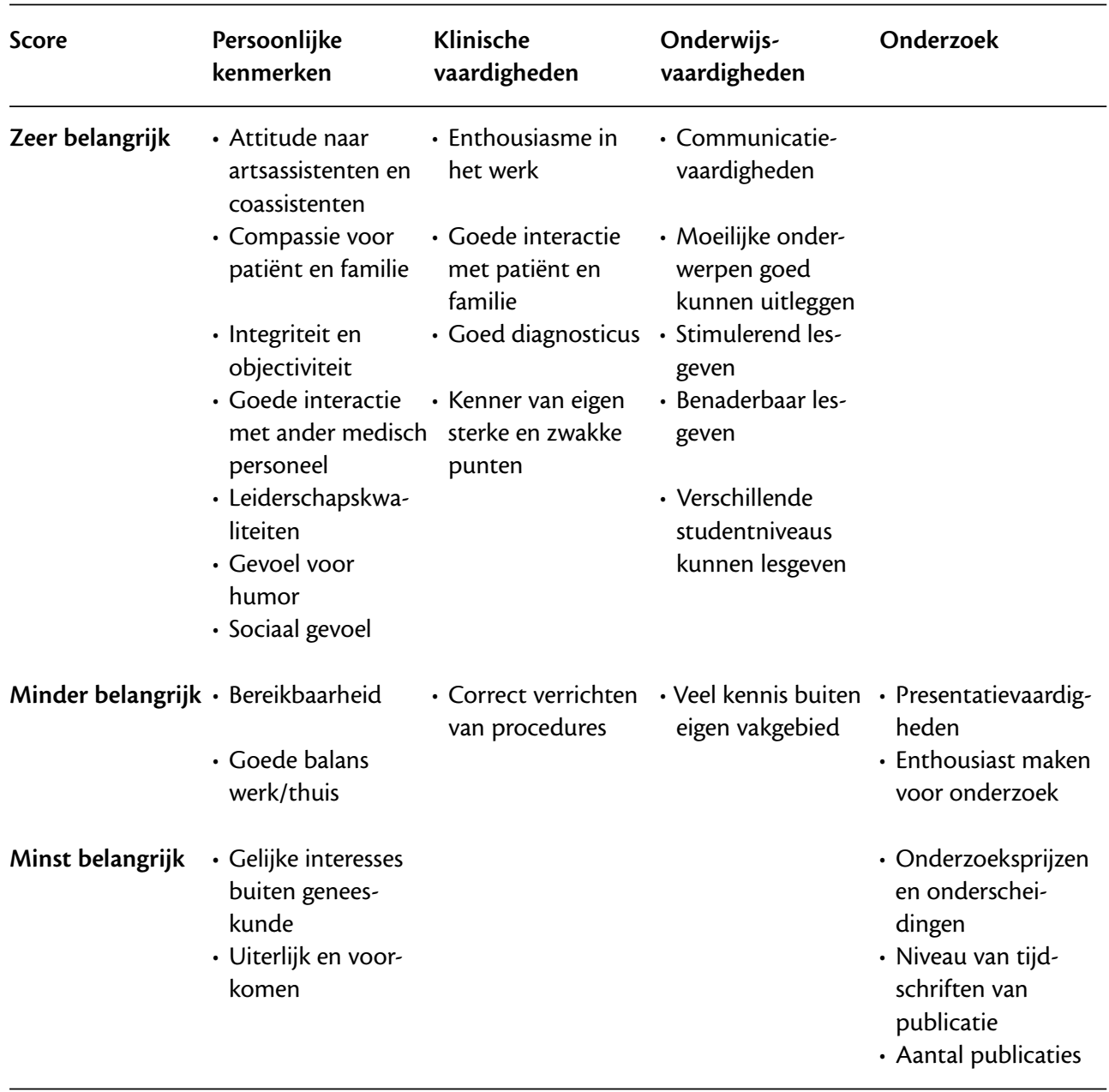


- tijd besteden aan artsassistenten en coassistenten;

- les hebben gehad in onderwijs geven;

- nadruk leggen op patiëntenbelang en op het geven van goede feedback (goede onderwijsstijl);

- onderwijs geven leuk vinden;

- een relatie opbouwen met artsassistenten:

- veel tijd besteden aan onderwijs.

De positie van een arts (bijvoorbeeld als hoogleraar) en zijn/haar onderzoeksstatus (het al dan niet gepubliceerd hebben van belangrijke artikelen) worden als minst belangrijk ervaren. 1217

In een ziekenhuis werken veel artsen, maar slechts een aantal daarvan zullen door studenten gezien worden als rolmodel. Het verschil tussen een arts-docent en een rolmodel werd in de studie van Althouse et al. toegeschreven aan het vaker, beter en natuurlijker toepassen van de vier principes van 'modeling'. ${ }^{18}$ Ook zijn er persoonlijke kenmerken die een rolmodel onderscheiden van een 'gewone' arts. In vergelijking met 'gewone' artsen zijn rolmodellen coöperatiever, gaan ze meer uitdagingen aan en zien ze het oplossen van problemen vaker als een uitdaging. Ook zijn ze assertiever en energieker. De rolmodellen zijn minder snel boos of geagiteerd, minder sensatiebelust en minder cynisch. ${ }^{20}$

Een rolmodel heeft vanwege zijn eigenschappen een belangrijke voorbeeldfunctie voor aankomende artsen en artsassistenten. Maar wat is het effect van een rolmodel op toekomstige artsen?

\section{Effecten van een rolmodel}

Het effect dat een rolmodel heeft op een student of artsassistent is groot. Niet al- leen zorgt hij of zij voor beter onderwijs voor studenten ${ }^{12-13} 19$ en voor een goede vorming van artsen door een voorbeeld te zijn op het gebied van ethiek en gedrag, ${ }^{14-}$ 1519 rolmodellen hebben ook invloed op de carrièrekeuze van de student.

Wright vond bij 57\% van de studenten dat hun rolmodel invloed had op hun beroepskeuze. ${ }^{13} \mathrm{Er}$ is een associatie tussen de blootstelling aan rolmodellen en het kiezen voor een carrière. Hoe vaker een rolmodel wordt gezien, hoe groter de kans dat een student kiest voor zijn of haar specialisme.

Van de mannen had 85\% een mannelijk rolmodel en van de vrouwen had $41 \%$ een vrouwelijk rolmodel. Het percentage vrouwen in het betreffende ziekenhuis was $28 \%$. Dit betekent dat, hoewel vrouwelijke studenten vaker in contact komen met mannelijke artsen, ze toch vaak een vrouwelijke arts als rolmodel kiezen.

Basco et al. onderzochten wanneer studenten hun rolmodel ontmoeten. ${ }^{16}$ De meerderheid van de studenten ontmoet hun rolmodel tijdens de medische studie, vóór het maken van een specialismekeuze. De rolmodellen die tijdens de studie bekend worden, kunnen van invloed zijn op de specialismekeuze van studenten.

Henderson et al. laten zien dat contact met internisten tijdens een coschap interne geneeskunde zorgt voor een groter percentage studenten dat na de studie kiest voor een toekomst in dit vak. ${ }^{3}$ De kans dat studenten kiezen voor een carrière in de interne geneeskunde is drie keer groter als deze studenten tijdens het coschap in contact komen met internisten: de Odds-ratio (OR) is 3.1.* Hoe vaker er contact is met de internisten, hoe groter deze kans wordt. De internisten fungeren als rolmodel voor hun beroep.

\footnotetext{
* Odds-ratio (OR) is de verhouding tussen de determinant en de uitkomst, in dit geval tussen het contact met internisten en de beroepskeuze voor het vak interne geneeskunde. De OR moet groter zijn dan 1.
} 
Connelly et al. vinden in hun onderzoek dat het hebben van een rolmodel in de primary care (de benaming van basiszorg in verschillende landen, vergelijkbaar met de eerstelijnszorg in Nederland) het grootste effect heeft op het kiezen van primary care (PC) als carrière. Dit effect is groter dan dat van andere invloeden zoals socio-economische status en geslacht. ${ }^{21}$ Het effect van een PC-rolmodel in vergelijking met dat van een non-primary care (NPC) rolmodel geeft een OR van 6.5 als het gaat om de keuze voor een carrière in de primary care. Het hebben van een PCrolmodel versus het ontbreken van een rolmodel heeft een OR van 2.8. Voor artsassistenten heeft een rolmodel in de primary care versus een rolmodel in de nonprimary care een nog grotere invloed op het plannen van een carrière in de basiszorg $(\mathrm{OR}=18.0)$. Omgekeerd geldt ook dat studenten die geen rolmodel hebben en die niet zijn gestimuleerd door stafleden waarschijnlijk kiezen voor een carrière in de non-primary care. Uit dit onderzoek blijkt dus dat het hebben van een PC-rolmodel een grote positieve invloed heeft op het kiezen van een PC-carrière.

Burack et al. onderzochten het verschil tussen PC- en NPC-artsen. ${ }^{2}$ Het bleek dat de invloed van rolmodellen op de carrièrekeuze bij de PC-groep groter was dan bij de NPC-groep (respectievelijk $30 \%$ vs $5 \%$ ). De artsen in de PC-groep werden in hun beroepskeuze direct beïnvloed door het rolmodel. Artsen in de NPC-groep hadden wel rolmodellen, maar lieten hun carrièrekeuze niet door deze mensen beïnvloeden: zij werden meer beïnvloed door het kunnen verrichten van procedures en het nemen van snelle beslissingen. Het aantal vrouwen dat koos voor een PC-carrière was groter dan het aantal mannen.

Martini et al. laten zien dat de beroepskeuze afhankelijk is van verschil- lende factoren. ${ }^{4} \mathrm{Er}$ is een significante associatie tussen oudere studenten en vrouwelijke studenten en de beroepskeuze voor primary care. Het al dan niet kiezen voor een toekomst in de primary care hangt volgens deze studie ook af van het curriculum. Als er tijdens de studie aandacht wordt gegeven aan de primary care, middels onderwijs en stage, dan komen er meer sollicitanten. De aanwezigheid van een coschap primary care heeft een significant positieve invloed op het aantal artsen dat zich aanmeldt voor deze opleiding (correlatie 0.4; $\mathrm{p}<0.01$ ) Dit kan te danken zijn aan het vergrote aantal contacturen met mogelijke rolmodellen.

Campos-Outcalt et al. zijn iets voorzichtiger in hun conclusies. ${ }^{22}$ In hun review geven ze aan dat het mogelijk is dat studenten kiezen voor een bepaalde carrière na het ontmoeten van een rolmodel in dit vak, maar dat het ook zo kan zijn dat de studenten al hebben gekozen voor een bepaald vak en dan toekomstige collega's als rolmodel zien.

Cochran et al. schrijven dat rolmodellen voor de keuze voor het vak chirurgie geen grote rol spelen. ${ }^{1}$ De studenten die kiezen voor de chirurgie als carrière hebben meestal geen rolmodel of mentor in dit vakgebied, terwijl de studenten in deze studie die hebben gekozen voor een ander specialisme dit duidelijk wel hebben. Van de studenten die wel een rolmodel in de chirurgie hadden, had dit rolmodel een positieve invloed op de keuze. Er was in dit onderzoek geen verschil tussen mannelijke en vrouwelijke studenten.

Neumayer et al. laten zien dat, hoewel veel vrouwen kiezen voor de studie geneeskunde, maar weinig vrouwen solliciteren voor de opleiding chirurgie. ${ }^{23} \mathrm{De}$ geïnterviewde vrouwen gaven aan dat een tekort aan vrouwelijke rolmodellen in de chirurgie hier een reden voor zou kunnen zijn. Slechts één vijfde van de vrouwelijke 
studenten had contact gehad met een vrouwelijke mentor tijdens het coschap chirurgie.

In een ander onderzoek van Neumayer et al. kwam naar voren dat $8 \%$ van de vrouwelijke ondervraagden als specialisme koos voor de chirurgie. ${ }^{24}$ Van deze vrouwen kwam $88 \%$ van een faculteit waar veel vrouwelijke chirurgische rolmodellen zijn.

\section{Discussie}

Zes studies vinden een positieve relatie tussen het beschikken over een rolmodel en de beroepskeuze van de student. ${ }^{2-5} 13$ ${ }^{21}$ In één review komt dit positieve effect echter niet naar voren. ${ }^{22}$ Eén studie ${ }^{1}$ vindt geen duidelijk positief effect van rolmodellen op de keuze voor een carrière in de chirurgie. De review dateert uit 1995, de onderzoeken die in dit artikel zijn gebruikt zijn bijna allemaal na 1995 gepubliceerd en niet gebruikt in de review.

Twee studies geven aan dat vrouwelijke rolmodellen in de chirurgie een belangrijke rol kunnen spelen in de keuze van vrouwelijke studenten voor het beroep van chirurg. ${ }^{23-24}$ In de vragenlijsten die in deze onderzoeken zijn gebruikt, werd gebruik gemaakt van stellingen waar de respondenten op moesten reageren in de vorm van een vijfpuntsschaal (van 'helemaal mee eens' tot 'absoluut mee oneens'). De vragen waren echter enigszins suggestief en hierdoor is mogelijk bias opgetreden.

De onderzoeken waren verschillend van opzet, waardoor een goede vergelijking niet helemaal te maken is. In zeven studies werd de vragenlijst ingevuld door respondenten die binnenkort zouden afstuderen of al afgestudeerd waren. 1241316 23-24 In één studie werden studenten tijdens en vlak na het afronden van de studie ondervraagd. ${ }^{21}$ In één studie werden studenten voor en na het coschap interne genees- kunde ondervraagd. ${ }^{14}$ Het tijdstip waarop een onderzoek wordt afgenomen, voor of na de studie, is van belang voor de uitkomst. Het is mogelijk dat artsen voor een specialisatierichting hebben gekozen na het ontmoeten van een rolmodel. Maar mogelijk hadden ze hun specialismekeuze al gemaakt en hebben ze in dat specialisme een rolmodel gevonden. In de studies werd hier geen onderscheid tussen gemaakt.

Een eenduidige conclusie kan aan de hand van de beschreven onderzoeken niet worden getrokken, maar een rolmodel lijkt een positieve invloed uit te kunnen oefenen op studenten. Van dit gegeven kunnen universiteiten gebruik maken.

\section{Het gebruik van rolmodellen}

Voor ieder specialisme is het van belang dat er studenten zijn die het vak boeiend vinden en voor dit specialisme willen gaan kiezen. Omdat rolmodellen mogelijk een positieve invloed hebben op de beroepskeuze van studenten, zouden ze een rol kunnen spelen in het aantrekken van nieuwe artsen.

Ten eerste kwam uit verschillende onderzoeken het resultaat dat interactie met een rolmodel een positief effect heeft op de keuze voor het vakgebied van dit rolmodel.3-4 13 Van dit gegeven kunnen faculteiten en vakgroepen gebruik maken. Door studenten tijdens de gehele studie (tijdens werkgroepen en colleges) en de coschappen meer in contact te laten komen met rolmodellen, zullen mogelijk meer studenten kiezen voor een carrière in hun richting. 1316 Door studenten vroeg in de studie met veel rolmodellen uit verschillende vakgebieden in contact te brengen, is een goede afgewogen keuze uiteindelijk mogelijk.

Ten tweede speelt het gedrag van een rolmodel een belangrijke rol bij de ontwikkeling van toekomstige artsen. ${ }^{13}$ Voor de specialismen is het daarom van belang 
de juiste artsen op de juiste plaats te zetten. Het is bekend welke eigenschappen als belangrijk worden beschouwd voor een rolmodel, namelijk persoonlijke kenmerken, klinische vaardigheden en onderwijsvaardigheden. ${ }^{12} 19$ Door artsen met deze eigenschappen te herkennen en op te leiden als docenten, worden de rolmodellen adequaat ingezet. ${ }^{12-13} 15$ Deze artsen horen op een positie waar ze veel met studenten in contact komen. ${ }^{12-13} 15$ Andersom geldt ook dat artsen die geen affiniteit hebben met onderwijs en dus waarschijnlijk geen goede rolmodellen zullen zijn, beter niet op plekken kunnen zitten waar ze veel les moeten geven en in contact komen met studenten. ${ }^{12-13}$

Ten slotte lijkt voor het kiezen voor het specialisme chirurgie het rolmodel niet zo'n grote rol te spelen, terwijl dit bij alle andere specialisten wel zo is. ${ }^{1}$ Dit zou kunnen komen doordat er geen behoefte is aan rolmodellen in de chirurgie, maar het kan ook zo zijn dat er een gebrek is aan rolmodellen.

Voor vrouwelijke studenten zou een vrouwelijk rolmodel in de chirurgie een positieve rol kunnen spelen in de beroepskeuze. ${ }^{21-22}$ Vrouwelijke studenten verwachten dat vrouwelijke chirurgen niet tevreden zijn met hun baan, terwijl deze chirurgen zeggen dit wel te zijn. ${ }^{22}$ Meer contact met een vrouwelijk rolmodel in de chirurgie zou een positiever beeld kunnen geven van het vakgebied en meer vrouwen kunnen aantrekken.

Het bovenstaande geldt waarschijnlijk niet alleen voor de chirurgie. Het aantrekken van mogelijke rolmodellen binnen een vakgebied en deze een belangrijke plaats in het onderwijs geven, zal zorgen voor interesse in het betreffende vak.

\section{Conclusie}

Rolmodellen kunnen belangrijk zijn voor de ontwikkeling en specialismekeuze van aankomende artsen. Door specialisten meer inzicht te geven in de 'rol van het rolmodel', kan beter ingesprongen worden op de behoefte van zowel student als vakgroep. Specialismen die niet populair zijn, kunnen gebruik maken van hun rolmodellen bij het onderwijs en de stages, om zo mensen aan te trekken.

\section{Literatuur}

1. Cochran A, Spencer M, Neumayer LA. An internet-based survey of factors influencing medical student selection of a general surgery career. Am J Surg 2005;189:742-6.

2. Burack JH, Irby DM, Carline JD, et al. A study of medical students' specialty-choice pathways: trying on possible selves. Acad Med 1997;72:53441

3. Henderson MC, Hunt DK, Williams JW. General internists influence students to choose primary care careers: the power of role modelling. Am J Med 1996;101:648-53.

4. Martini CJ, Veloski JJ, Barzansky B, Xu G, Fields SK. Medical school and student characteristics that influence choosing a generalist career. JAMA 1994;272:661-8.

5. Brouns M, Schokker A. Arbeidsvraagstukken en sekse. Trendrapport 2 STEO. Den Haag: Ministerie van Sociale Zaken en Werkgelegenheid, DOP; 1990.

6. Registratie van beroepen in de gezondheidszorg [database op internet]. NIVEL [geciteerd op 02-082006]. NIVEL-beroepenregistraties 2005. Beschikbaar op: http://www.nivel.nl/beroepenindezorg/.

7. Meyboom B. Emancipatie van de (huisarts)geneeskunde. Afscheidscollege van prof. dr. B. Meyboom-de Jong op 28 september 2004.

8. Takkenberg JJM, Visser MC, Kenter GG. Vrouwen gezocht in topfuncties. Med Contact 2005;11:452-4.

9. Andrews NC. The other physician-scientist problem: where have all the young girls gone? Nat Med 2002;8:439-41.

10. Harting A. De ideale arts. VNVA-krant 2005;33: 10-1.

11. Van Dale Taalweb. Van Dale hedendaags Nederlands [database op internet]. Van Dale Lexicografie bv; 2006 [geciteerd op 02-08-2006]. Beschikbaar op: http://www.vandale.nl/opzoeken/woordenboek.

12. Wright SM. Examining what residents look for in their role models. Acad Med 1996;71:290-2.

13. Wright SM, Wong A, Newill C. The impact of role models on medical students. J Gen Intern Med 1997;12:53-6.

14. Wright SM, Kern DE, Kolodner K, Howard PM, Brancati FL. Attributes of excellent attending-physician role models. N Engl J Med 1998;339:1986-93. 
15. Wright SM, Carrese JA. Serving as a physician role model for a diverse population of medical learners. Acad Med 2003;78:623-8.

16. Basco WT, Reigart JR. When do medical students identify career-influencing physician role models? Acad Med 2001;76:380-2.

17. Bandura A. Social learning theory. Englewood Cliffs: Prentice-Hall; 1977.

18. Althouse LA, Stritter FT, Steiner BD. Attitudes and approaches of influentioal role models in clinical education. Adv Health Sci Educ Theory Pract 1999;4:111-22.

19. Elzubeir MA, Rizk DEE. Identifying characteristics that students, interns and residents look for in their role models. Med Educ 2001;35:272-7.

20. Hojat M, Nasca TJ, Magee M, Feeney K, Pascual $\mathrm{R}$, Urbano $\mathrm{F}$, et al. A comparison of the personality profiles of internal medicine residents, physician role models, and the general population. Acad Med 1999;74:1327-33.

21. Connelly MT, Sullivan AM, Peters AS, Clark-Chiarelli N, Zotov N, Martin N, et al. Variation in predictors of primary care career choice by year and stage of training. J Gen Intern Med 2003;18:15969.

22. Campos-Outcalt D, Senf J, Watkins A, Bastacky S. The effects of medical school curricula, faculty role models, and biomedical research support on choice of generalist physician careers: a review and quality assessment of the literature. Acad Med 1995;70:611-9.

23. Neumayer L, Konishi G, L'Archeveque D, Choi R, Ferrario T, McGrath J, et al. Female surgeons in the 1990s. Academic role models. Arch Surg 1993; 128:669-72.

24. Neumayer L, Kaiser S, Anderson A, Barney L, Curet M, Jacobs D, et al. Perceptions of women medical students and their influence on career choice. Am J Surg 2002;183:146-50.

\section{De auteurs:}

Mw. J. van den Berg is zesdejaars geneeskundestudent in het UMC Utrecht.

Mw. dr. J.J.D.J.M. Rademakers is programmaleider kwaliteitszorg, ontwikkeling en onderzoek bij het Expertisecentrum voor onderwijs en opleiding, Directie onderwijs en opleidingen, UMC Utrecht.

Prof. dr. Th.J. ten Cate is directeur van het Expertisecentrum voor onderwijs en opleiding, Directie onderwijs en opleidingen, UMC Utrecht.

Correspondentieadres:

Mw. dr. J.J.D.J.M. Rademakers, UMC Utrecht, Expertisecentrum onderwijs en opleiding (dOO), HB .05, Postbus 85500, 3508 GA Utrecht.

Belangenconflict: geen gemeld.

Financiële ondersteuning: geen gemeld.

\section{Summary}

Introduction: The choice of a specialty by medical students is affected by many different factors. Personal characteristics and experiences in different specialties play a part as well as various role models. The lack of female role models may explain the under-representation of female specialists and full professors in medicine. Special features of role models, the effects and the possible use of role models were investigated. Whenever possible, the difference between male and female students was reported.

Method: A literature search of the national and international literature was performed using Medline and other search tools.

Results: The search yielded 10 relevant articles about the influence of role models on medical students' choice of specialty. Six studies reported a positive relationship between role models and specialty choice. One study reported no positive effect. Two studies showed that female role models can play an important role in attracting female students into surgery.

Conclusion and discussion: Role models can play an important role in medical students' choice of specialty. Universities and specialties can make use of this fact by ensuring that students are presented with role models at suitable stages during the curriculum. (Van den Berg J, Rademakers JJDJM, Ten Cate ThJ. The influence of role models on the specialty choice of future doctors. Dutch Journal of Medical Education 2006;25(5):227-234.) 